\title{
La educación indígena y los educadores en el Congreso Centroamericano de 1893
}

\author{
Indigenous Education and the Educators \\ at the 1893 Central American Congress
}

\author{
Amalia Nivón Bolán \\ Universidad Pedagógica Nacional, Unidad Ajusco \\ amalianivón@yahoo.com.mx
}

\begin{abstract}
Resumen
En el caso del Congreso Centroamericano de 1893, las formas de relación entre profesores y promotores de las reformas educativas en la educación primaria aportan elementos que hacen visible el pensamiento liberal positivista como forma de gobierno, mediante argumentos pedagógicos de organización de la escuela. Se reflexiona acerca de las inquietudes de los educadores centroamericanos ante la preocupación de cómo el Estado debe civilizar a la "raza indígena", en el sentido de inculcar costumbres e ideas de progreso de las naciones civilizadas.

El análisis de los congresos educativos permite aproximarnos al pensamiento, actuación y vínculos profesionales de los educadores, comprendiendo sus intereses comunes, particulares, posiciones, acuerdos y diferencias; con lo que se pretende analizar el tejido intelectual de la época en diferentes entornos latinoamericanos. Las interacciones locales y regionales de actores organizados y reconocidos por el Estado, influyen de manera significativa en lo que debe ser y hacer la escuela en los diferentes sectores de la sociedad, distinguiendo necesidades y condiciones particulares.

A través de la prensa educativa de la época y estudios recientes, se va reconstruyendo el pensamiento de los educadores, sus acciones y trayectorias profesionales, para entender la historia de la educación en contextos particulares y establecer relaciones de semejanza y diferencia en distintos contextos educativos.
\end{abstract}

Palabras clave: indígenas. maestros, congresos.

\section{Abstract}

In the case of the 1893 Central American Conference, analysis of the relationship between teachers and advocates for the reform of primary education, contributes elements that make visible the libe- 
ral, positivist form of government through educational arguments concerning the organization of schooling. The Central America Conference reflects their concerns on how the State should civilize "the indigenous race" in order to inculcate the habits and ideas of progress of civilized nations. The analysis of educational conferences allows us to approach the thoughts, actions and professional ties of educators. By understanding their common and individual interests, their positions, their agreements and disagreements, we can analyze the intellectual fabric of this period in different Latin American settings. Interactions between local and regional actors, organized and recognized by the State, have a significant influence on ideas about what schools should be and do in relation to different sectors of society, by distinguishing needs and particular conditions. In this article, educators' thoughts, career paths and actions are reconstructed through reports in the educational press of the time and contributions of recent studies. This leads to understanding of the history of education in particular contexts, while establishing differences and similarities through various contexts.

Key words: Indians, educators, educational conference, State, Central America.

\section{Introducción}

A lo largo de la segunda mitad del siglo XIX se realizaron foros educativos en distintos países europeos y del continente americano, organizados a iniciativa de educadores y especialistas, cercanos al pensamiento de los poderes políticos, económicos y culturales, y derivados de los movimientos sociales independentistas a favor de la construcción de entidades nacionales. En general, en las últimas dos décadas las asambleas y congresos educativos abordaron diferentes aspectos de la instrucción y organización escolar, a favor de la política de los Estados nacionales. Temas aún discutibles por educadores en los diferentes sistemas educativos de sus contextos socioculturales e históricos.

En los congresos pedagógicos de finales del siglo xix y principios del xx se discutieron ideas y estrategias que definieron rumbos y tareas sustantivas de la educación primaria elemental y complementaria. En la prensa latinoamericana circulaban ideas pedagógicas comunes a los temas que se debatían en congresos europeos, pero también hubo temas de interés local, derivados de las particularidades del contexto sociocultural y político de los grupos con mayor poder de decisión en términos de fuerza política, para alcanzar acuerdos como formas de cohesión entre los sectores participantes. A través de estos comunicados se dio a conocer al público en general y a los educadores en particular, los temas y acuerdos alcanzados en distintos congresos educativos de la región.

Por ejemplo, en 1882 la revista argentina El Monitor de la Educación Común (vol. 1, núm. 1 al 20) da a conocer que el educador Domingo F. Sarmiento (1811-1888), a través del Ministerio de Instrucción Pública, da impulso a la realización del Congreso Pedagógico 
Internacional Americano, denominado también Congreso de Educación Común, donde se discutió y aprobó la legislación nacional de la educación pública argentina. En esa época los vínculos entre Argentina, Chile y Uruguay eran estrechos, y las conclusiones del Congreso tuvieron resonancia de la enseñanza gratuita en las escuelas comunes de Uruguay y Chile. Ese mismo año, en México, el presidente del Consejo Superior de Salubridad, Ildefonso Velasco ( ¿-1884), convocó la realización del Congreso Higiénico Pedagógico, bajo la idea de perfilar el modelo de una educación pública semejante a las condiciones de las escuelas europeas, acorde con medidas de higiene para el funcionamiento del inmueble, el mobiliario, libros y útiles escolares, el método de enseñanza, las edades de los escolares, los ejercicios corporales, y los cuidados para evitar la transmisión de enfermedades en las escuelas (Meneses 1998: 365-367). Tres años después, en 1885, el Ministro de Instrucción Pública de Argentina, Manuel D. Pizarro (1841-1909), Ilamó a un nuevo Congreso Pedagógico Nacional, y en 1889, la Sociedad de Profesores de Instrucción Primaria de la Escuela Normal de Preceptores de Santiago de Chile dio inicio al debate sobre la creación de una legislación de instrucción primaria obligatoria, fincada en la enseñanza del método fonético analítico sintético para la enseñanza simultánea de la lectura y escritura; con la participación del Instituto Pedagógico y la Universidad de Chile. Cuatro años más tarde, nuevamente en México, entre 1889 y 1890 se realizan el primer y segundo Congreso Nacional de Instrucción Pública, convocados por el Ministro de Instrucción Pública, en los cuales se acuerdan los programas nacionales de instrucción primaria y los de las escuelas normales.

En estas publicaciones se observa una nota breve enviada en 1892 desde la ciudad de Guatemala por el profesor chiapaneco mexicano, Sóstenes Esponda (1845-1921), a la revista México Intelectual (1892: 337-339) de la Normal de Jalapa, en Veracruz, México; en la cual se anuncia la celebración del primer Congreso Pedagógico Centro Americano (CPC), así como la primera Exposición Escolar Nacional, a finales de 1893. Esta nota da origen al trabajo que aquí se presenta, con el interés de analizar algunas preocupaciones de profesores y educadores participantes en el CPC de 1893; en particular al tratar el tema de apertura: ¿cuál será el medio más eficaz para civilizar a la raza indígena, en el sentido de inculcarle ideas de progreso y hábitos de pueblos cultos?

La intención es destacar el valor que tienen los documentos o actas de los congresos pedagógicos como una forma de reconstrucción de las preocupaciones y puntos de vista de los actores educativos: profesores, inspectores, directivos, funcionarios, académicos y artistas, involucrados en el debate y definición del proyecto institucional de la escuela primaria en esa época. La revisión de los trabajos de las comisiones del CPC, publicados en 1894 a manera de Memoria por los educadores Santos Turiño (1831-1914) y Darío González (1836-1911) en la Tipografía Nacional del Gobierno de Guatemala, permitió reconstruir el tejido social del imaginario educativo de educadores y funcionarios en torno a la enseñanza. Las ponencias 
documentadas contribuyen a mostrar las distintas maneras de enfocar y explicarse los educadores los principales problemas que Centroamérica enfrentaba.

Cabe señalar que en este primer tema del congreso, los participantes resaltan el entorno guatemalteco como el de mayor población indígena. La zona con más asentamientos étnicos era desde entonces Guatemala ${ }^{1}$ y el sureste mexicano, ${ }^{2}$ Honduras, ${ }^{3}$ Nicaragua, ${ }^{4}$ Costa Rica ${ }^{5}$ y El Salvador. ${ }^{6}$ La caracterización etnográfica respondía a la delimitación de los terrenos del régimen colonial, que determinaba las condiciones de dominación y explotación de los pueblos indígenas. Para Ordóñez Cifuentes (1991), a lo largo del siglo XIx las nuevas fronteras nacionales restringieron violentamente los territorios indígenas y los pueblos quedaron sujetos a controles político-administrativos y culturales de los nuevos Estados, sin admitirse ningún reconocimiento a la personalidad política de estos pueblos.

La búsqueda de elementos biográficos de los actores resulta relevante también porque permite comprender en el discurso de los congresistas sus diferencias y acuerdos sobre la manera de entender el papel de la escuela primaria. Había educadores de ideas liberales, conservadoras, religiosas, positivistas, afirmativas y negativas hacia los indígenas; había docentes, directores universitarios y representantes nombrados por el Ejecutivo nacional; muchos de ellos además realizaban actividades literarias, médicas, de ingeniería, jurisprudencia, periodismo, investigación, lo que les permitía ampliar el horizonte de su formación y ser escuchados con una mayor resonancia en otros espacios sociales. Los perfiles de los asistentes contribuyen a darle voz a los congresos, tanto en su convocatoria como en la difusión de las ideas, debates y conclusiones. Los documentos de los congresos nos arrojan nuevos textos con interrogantes sobre cómo mirar los distintos procesos de configuración de los sistemas escolares en los distintos contextos en que se desarrollan.

\footnotetext{
${ }^{1}$ Los educadores del congreso no se refieren por nombre a los diferentes grupos étnicos de Guatemala: Quichés, Mames, Pocomames, Mayas y Choles.

${ }^{2}$ Al momento de la realización del Congreso Pedagógico Centroamericano, Chiapas ya no pertenecía a Guatemala, donde habitaban Tzotziles, Tzeltales, Zoques, Choles, Tojolabales, Lacandones, Mames, Chujs, Jacaltecos, Motocintlecos Kaxchiqueles.

El historiador guatemalteco Julio Cambranes señala que después de los "arreglos" de Chiapas entre Porfirio Díaz y Justo Rufino Barrios, el primero decidió llevar adelante sus planes anexionistas, provocando un conflicto con Guatemala en septiembre de 1887, y agrega de dados los intereses del Imperio Alemán en Guatemala, éste advierte al gobierno mexicano que vería con muy malos ojos cualquier intervención militar de México en la República de Guatemala. Mediación que influyó en la firma del Tratado de Comercio de 1887 entre Alemania y Guatemala, respectivamente (Canabrias, 1977; Ordóñez, 1991: 192)

3 Entre los grupos étnicos de Honduras se encuentran los Garífunas, los Jicaques, los Chortis, los Lencas, los Miskitos, los Paya y los Sumus.

${ }^{4}$ En Nicaragua se encuentran Miskitos, Sumus y Ramas.

${ }^{5}$ En Costa Rica, en lugares de reserva habitan los Cabecar, los Bribri, los Guaymi, los Terraba y Boruca y los Maleku.

${ }^{6}$ En El Salvador habitan Nahuats, Lencas, Cacaoperas y Chortis
} 
Los trabajos del CPC de 1893 tienen lugar en el marco de la política liberal del gobierno guatemalteco, y de manera específica se deben al interés de educadores cercanos a esta política, interesados en impulsar un modelo pedagógico acorde a las iniciativas de enseñanza primaria elemental y complementaria existente en otros países de Hispanoamérica y Estados Unidos. La organización del Congreso estuvo a cargo de la Academia Central de Maestros (ACM) de Guatemala, organización reconocida por el Ministerio de Justicia e Instrucción Pública de ese país. Los temas pedagógicos planteados en el CPC se agruparon en ocho grupos a manera de preguntas: la escuela y los indios, la unificación de la enseñanza en CentroAmérica, las escuelas de párvulos o preparatoria a la elemental, la organización de las escuelas elementales y superior o complementaria, las escuelas Normales, la inspección escolar, el trabajo manual en las escuelas y el internado en los establecimientos de educación.

\section{Antecedentes}

Desde que se constituyó en 1824 la República Federal de Centroamérica, integrada por cinco estados: Guatemala, El Salvador, Honduras, Nicaragua y Costa Rica, ${ }^{7}$ las élites criollas y europeas con intereses políticos, comerciales e intelectuales establecieron vínculos de autonomía, con acuerdos jurídicos comunes, como la abolición de la esclavitud, el reconocimiento de un solo idioma, la extinción de lenguas indígenas, el establecimiento de cargos y empleos para la gente alfabetizada, la exención del pago de tributos por el uso de calzado y la vestimenta ladina para los indios. La influencia del pensamiento positivista en la forma de gobierno de las naciones independientes de América Latina, especialmente durante las últimas décadas del siglo XIX, se fue transformando de acuerdo con las particulares circunstancias de los países y regiones. En muchos casos las políticas adoptadas por influencia del positivismo significó el ascenso de nuevos grupos liberales, necesitados de materializar sus ideas de progreso y modernidad en acciones que dieran orden a la convivencia colectiva. Desde la perspectiva de Artemis Torres Valenzuela (2010: 98), la llegada del positivismo a Guatemala se hace evidente a partir de 1865, con el conocimiento de nuevas formas de conocer las cosas, los fenómenos y de entender al hombre. Se trataba de novedosas ideas que se adoptaban y se adaptaban a la particularidad guatemalteca: "El concepto de civilización separaba a los pueblos bárbaros, salvajes y paganos de los cultos y cristianos. Lograr la civilización era uno de los principales ideales". Señala este autor que durante esos años los países del área centroamericana vivían un momento de turbulencia política y de constantes amenazas.

\footnotetext{
${ }^{7}$ En 1838 se formó un sexto estado, Los Altos, con capital en la ciudad de Quetzaltenango, con los territorios del occidente de Guatemala, y parte del actual Soconusco de Chiapas, México. El territorio de la Federación también incluía Belice.
} 
Para mantener el poder y ante el temor de un desequilibrio las autoridades del gobierno expresaban que todo transcurriría en orden y marchaba hacia delante; sin embargo la necesidad de expresar y justificar ese orden indicaba preocupaciones de fondo. El pensamiento positivista fue considerado una directriz de mando que daba certeza de la perfección que quería lograrse por el camino del progreso y la paz social. Para Ordóñez Cifuentes (1991: 83-84), los prejuicios coloniales de criollos, inauguraron en Centroamérica y particularmente para el caso guatemalteco, el colonialismo interno y la constitución del estado etnocrático. En la mentalidad de los independistas y liberales criollos, los principios rousseaunianos y del capitalismo de Adam Smith van adquiriendo a lo largo del siglo XIX presencia política, militar y económica para encontrar rutas de integración social, geográfica y política en Centroamérica y el Caribe, y favorecer el manejo de los recursos naturales y de las poblaciones. Añade el autor que durante los gobiernos guatemaltecos de Justo Rufino Barrios (1873-1885), Manuel Lisandro Barillas (1885-1892), José María Reina Barrios (1892-1898) y de Estrada Cabrera (1898-1920) inicia el capitalismo agrario, rompiendo con el poderío feudal terrateniente y clerical de la iglesia católica, heredado del régimen colonial, y con los derechos de ocupación de la propiedad comunal indígena. Se fortalece el Estado nacional con el reordenamiento del marco jurídico laboral de la propiedad de la tierra y del sistema educativo; se define la geografía del país; se constituye un sistema político centralista basado en el poder caudillista de liberales ladinos; se da impulso al proceso civilizatorio de la sociedad a través de la escuela.

La penetración del positivismo en la zona hizo que las ideas de progreso a través de la educación se fueran generalizando. Torres Valenzuela (2010: 105-106) señala que en 1867 se propuso dividir a la educación en Guatemala en siete categorías: la enseñanza primaria (lectura, escritura, doctrina cristiana, elementos de aritmética y posiblemente nociones generales), la enseñanza secundaria (ramos de las matemáticas, física, naturales, geografía, algunos idiomas vivos, moral y principios de religión), enseñanza clásica (lenguas antiguas, literatura y filosofía trascendental), enseñanza universitaria (jurisprudencia y medicina), la enseñanza eclesiástica (ciencias eclesiásticas del seminario), enseñanza profesional (ramos de las ciencias naturales, físicas y matemáticas) y la enseñanza industrial (agricultura, minería, comercio y ramos científicos de la industria). En materia indígena, en 1879 Justo Rufino Barrios emite un decreto para reglamentar el funcionamiento de una escuela especial para indígenas, enmarcando la política educativa para ellos. Edgar Barillas (1989: 54) cita una fracción del decreto publicado el 17 de febrero de 1883 en el Diario de Centro América: "Esos millares de indios, que ningún servicio prestan al país y más bien le perjudican, que viven alejados de los negocios públicos, y para quienes todo es indiferente, a quienes no perjudica jamás el porvenir, y no ven otra cosa que el presente, esos seres decimos, ya civilizados, 
contribuirán al progreso de su patria, haciéndose útiles y comprendiendo que el destino del hombre es el trabajo, y no el marasmo"8 (González Ponciano, 1991: 60).

\section{Contexto centroamericano a finales del $\mathbf{x I X}$}

La población indígena centroamericana se encontraba, como en otras partes del continente, en terrenos delimitados por el régimen colonial, en lugares dispersos, aislados o de difícil acceso. Según los datos registrados por el censo de 1893,9 la población guatemalteca no superaba el millón y medio de habitantes, de los cuales las dos terceras partes se estimaba eran indígenas dedicados a labores agrícolas; siguiéndole en grupo laboral importante las tortilleras y molenderas, después los hilanderos y tejedores, y por último los agentes diplomáticos, funcionarios del gobierno, profesores, fabricantes de tejidos, ebanistería, carpintería, calzado y los trabajadores del hierro. Este panorama socioeconómico, vinculado al pensamiento liberal de los grupos organizados cercanos al gobierno y a las instituciones: educativas, artísticas y culturales, contribuyó para forjar estrategias que dieran estabilidad social, política y económica a la región centroamericana.

A partir de la composición de la estructura social, se construye en el imaginario social la organización de los bienes nacionales, el trabajo y la mano de obra. El Estado liberal oligárquico requería de medidas legislativas, técnicas, y pedagógicas que favorecieran el buen uso de la mano de obra y la estabilidad social. Argueta (2011: 9-11) señala que el momento económico se acompaña del debate político de las diversas legislaciones en Centroamérica en torno a las formas de trabajo agrícola, que sólo favorecía a los dueños de la producción, sin beneficio alguno para los pueblos indígenas y el poder de los Estados nacionales. El 6 de abril y el 10 de octubre de 1893 se publica en el Diario de Centro América la Ley de Jornaleros y la Ley de Trabajadores, acordándose liberar las condiciones de sometimiento en que se encontraba la mano de obra agrícola. Refiere Argueta que la resistencia de los indios a la privatización de la mano de obra forzada impuesta por la Ley de mandamientos, se basaba en el endeudamiento masivo instalado por las municipalidades y fincas. Con estas reformas se reconoce por la vía jurídica al indio para que participe como ciudadano de las ventajas de la civilización, sin que ello afecte la productividad agrícola de las tierras centroamericanas, por el contrario se aspiraba que fuera más organizada y técnicamente eficiente conforme a las necesidades de exportación del mercado internacional.

Las acciones pedagógicas de la política liberal del gobierno de Reina Barrios se orientan a enfrentar el abismo existente del trato laboral que recibían los indios de los ladinos pro-

${ }^{8}$ Citado por González, 1991: 60..

9 "Población de la República", El progreso Nacional, del 16 de noviembre de 1894, en González Ponciano, 1991: 69. 
pietarios de los terrenos agrícolas. Se pretendió modernizar las formas de trabajo de la agro exportación para dar solidez a la nación guatemalteca. No podía continuar el sistema de trabajo basado en el endeudamiento masivo de los trabajadores y debía garantizarse, a los grupos con poder político y económico, una mano de obra disponible para realizar un trabajo agrícola calificado y barato.

Así, en octubre de 1892 se convoca a un concurso para recibir propuestas, las cuales serían premiadas en junio de 1894; se decreta ese mismo mes la creación del Instituto Agrícola de Indígenas; y, se acuerda la celebración del primer Congreso Pedagógico Centroamericano. La educación pasó a ser parte indispensable de la política liberal para que las poblaciones indígenas aprendieran modernas formas de trabajo agrícola y se comportaran como ciudadanos del régimen. El movimiento pedagógico internacional de países de Europa y de América contribuyó a la efervescencia del proyecto educativo de los Estados nacionales, promoviendo una enseñanza individual, gradual y uniforme, con principios científicos, de progreso y de civilización.

Al referirse González Ponciano a los indios de Guatemala durante los últimos años del siglo XIX, señala:

[...] que la construcción de la nacionalidad y del estado en la mayoría de los países de América Latina, está condicionada por la relación inicial, fundante, entre colonizado y colonizador, colonia y metrópoli, periferia y centro, atraso y progreso, subdesarrollo y desarrollo, historia y prehistoria, salvaje y civilizado, racional e irracional, antiguo y moderno, indio y ladino, y todo el juego de matices y dualidades que singularizan a nuestras sociedades y generan idiosincrasias, conciencias e identidades (1991: 58).

Plantea así que los proyectos nacionales están influidos por el pasado reciente y el acontecer neocolonial, esto es, por la contradicción cotidiana de opuestos que renuevan el racismo y el despojo.

Para otros estudiosos contemporáneos el concepto de racismo es nuclear en la realidad guatemalteca, porque reafirma la condición económica de dominación a través de la idea de un antimestizaje, sustentado en valores simbólicos que diferencia a los blancos y no blancos. Sustentan que el racismo ha sido una constante en la historia de Guatemala: en la conquista y colonización, en el periodo comprendido entre 1871 y 1944, denominado por la historia oficial "régimen liberal"; y recientemente en el conflicto armado interno durante los años sesenta hasta 1996 (Cómez Isa, 2004). Casaús Arzú (2010) señala la importancia de este término como categoría antropológica para entender las relaciones de dominación y de poder en la sociedad guatemalteca, considerándolo elemento histórico estructural que produce opresión, desigualdades económicas, de acceso a la educación y otras exclusiones sociales. El término es también tratado en la academia como etnocentrismo, racismo cultural, 
racismo institucional de Estado, racismo cotidiano, que forma parte de la internalización de formas de vida, expresiones y prácticas cotidianas. Añade Casaús que el concepto de racismo intelectual propuesto por Bourdieu (1978), incorpora en el habitus aquellas formas de interpretar el mundo, que nos ayudan a adecuarnos en mirar a los otros desde la cultura dominante, y a entender el comportamiento motivado por el inconsciente; es decir, "constatar las dimensiones ocultas e invisibles del racismo" (Bourdieu, 1978: 413-414). Para Bourdieu no hay un racismo, sino racismos: hay tantos racismos como grupos que tienen la necesidad de justificarse por existir como existen. "El racismo de la inteligencia es un racismo de clase, cuya reproducción, depende del capital cultural, capital heredado que tiene la propiedad de ser un capital incorporado y, por tanto, aparentemente natural, innato". Es lo que hace que los dominantes se sientan justificados de existir como dominantes, que se sientan de "una esencia superior. Todo racismo es un esencialismo y el racismo de la inteligencia es la forma de sociodicea característica de una clase dominante cuyo poder se basa en parte en la posesión de títulos que, como los títulos escolares, se consideran garantía de inteligencia" (Bourdieu, 1978: 67).

\section{Educadores que debaten sobre la educación del indio}

Los planteamientos de especialistas y educadores en torno al papel de la escuela primaria en esta región latinoamericana de características multiculturales, multiétnicas y plurilingües, nos adentra en la complejidad de cómo entender los elementos estructurales, asimilados y adecuados a las coyunturas de carácter político, económico, científico, técnico, religioso, literario. Los participantes en el CPC analizan su realidad con las herramientas que han aprendido y heredado de generaciones anteriores sobre el lugar que ocupan como responsables legítimos de la escuela. Hablan del indio reconociéndose diferente a él, ubicándolo en otro espacio social, cultural e histórico; han naturalizado como distintos el indio del ladino o blanco. Imaginan a la escuela pública como indispensable donde hombres y mujeres aprenderán a comportarse como ciudadanos, con obligaciones y buen trato a los demás.

Ya sea como ponentes o como firmantes de los puntos acordados, todos se encuentran inmersos en las instituciones escolares y vinculados a los sectores que han dado legitimidad a la educación pública del Estado. Sobresalen educadores con liderazgo y experiencia en la conducción de tareas propias del sistema escolar: docencia, dirección y supervisión escolar, producción de textos educativos para escuelas primarias y normales, además de mostrar interés en disciplinas como la literatura, la lingüística, las matemáticas, la historia y la geografía. Entre ellos están hombres y mujeres de entre 20 y 60 años. Todos residentes en Centroamérica y un gran número de ellos con experiencias profesionales en varios países de 
la región, incluyendo México, Colombia y España. En general se encuentran vinculados a la política educativa marcada por los Ministerios de Instrucción Pública, ya sea como docente de enseñanza primaria, media o superior; como inspectores o directivos de escuelas formadoras de profesores y profesoras, de universidades, escuelas de artes y oficios, museos, editoriales educativas, de literatura, ciencias, historia o geografía. También pertenecen a órganos magisteriales como la Academia Central de Profesores (ACP) de Guatemala, o a la Sociedad Pedagógica de El Salvador (véase cuadro 1).

Los puntos de vista son indicadores de las distintas lecturas que configuran el posicionamiento de la clase en el poder, y de manera inteligente los oradores analizan el papel que representa la escuela en la política nacional del Estado, junto con los valores predictivos del éxito que alcanzarán los conocimientos y destrezas aprendidas por los educandos. Toman la palabra Juan Fernández Ferraz, Carlos Gagino, Esteban Guardiola Cubas, Francisco A. Gamboa, Pilar Larrave de Castellanos y Vicenta Laparra de la Cerda. Firman las conclusiones 27 congresistas; algunos de ellos son ponentes.

\section{El indio en el imaginario educativo de 1893}

Juan Fernández Ferraz plantea que el indio, a lo largo de la historia de la conquista y del poblamiento de los territorios americanos en la colonia hasta finales del siglo XIX, se ha visto entre las acciones generadas por dominadores

[...] siempre fue deficiente y torcida de su propio sendero la enseñanza dada por los dominadores a los dominados, y por más que reconozcamos en gran parte la buena fe de los frailes en tamaña obra, á sus manos encomendada, cabe sostener en vista de los resultados y sostenemos enfáticamente que el grave error consistió y consiste aún en pretender sacar al indígena de todo lo suyo, [...]. Lo único que cabía en tiempos de la conquista y cabe ahora es mejorar sus condiciones paulatina y sucesivamente en su mismo modo de ser, sin destruir ni torcer locamente sus aptitudes, sin pretender transformar una raza en otra raza (CPC, 1893: 321).

Esteban Guardiola afirma que el indio pertenece a una rama "etnográfica" distinta a la europea, sometida por el conquistador español. Observa que el indio del siglo XIX se ha entregado a las más ruines tareas, vive embrutecido por la ignorancia; pero hubo un tiempo en

que formó pueblos autóctonos y levantó los cimientos de vastos y florecientes imperios; la que alcanzó un alto grado de civilización y poderío, llegando a contar en su seno sabios y artistas, agricultores y demás industriales; la que fundó establecimien- 


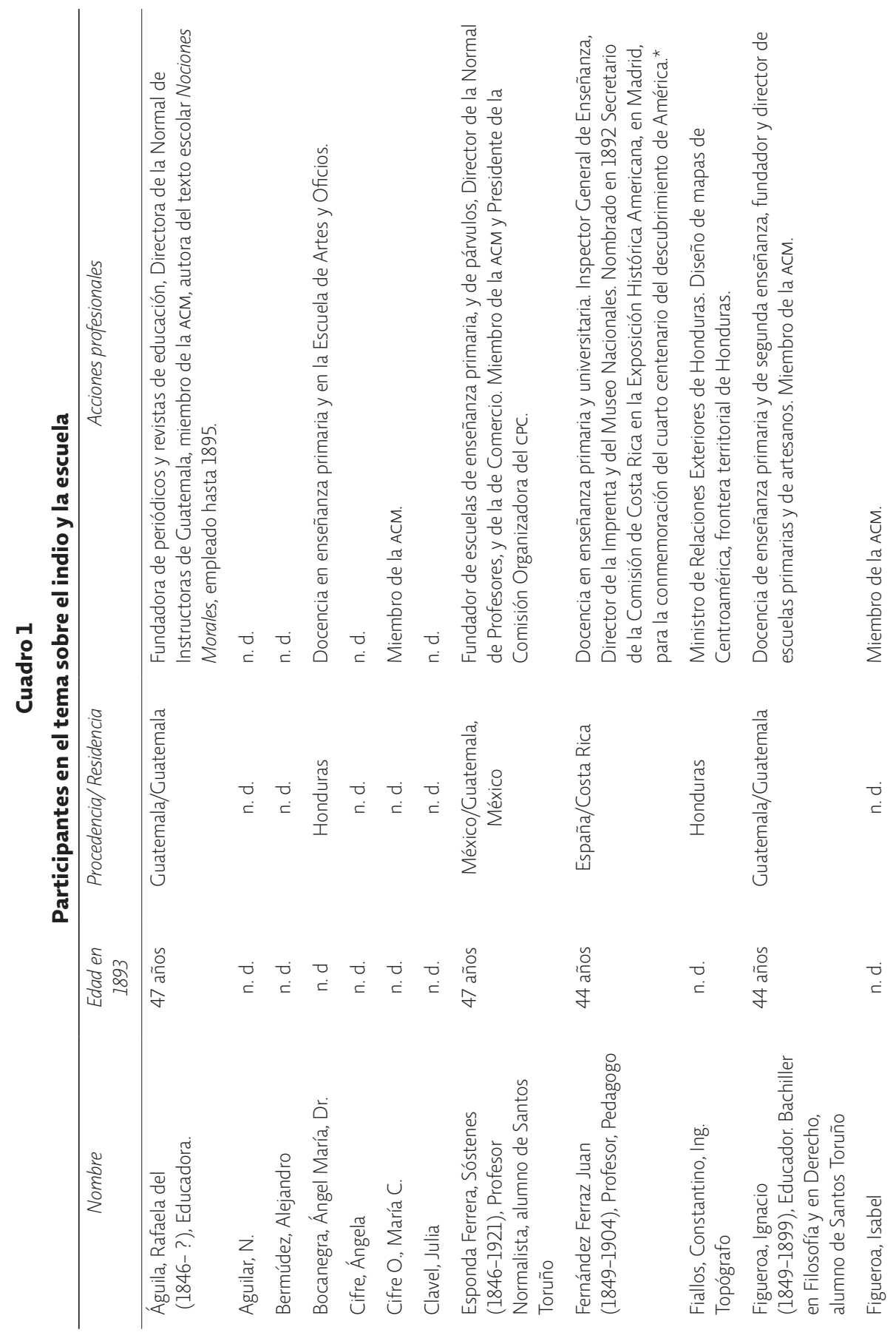




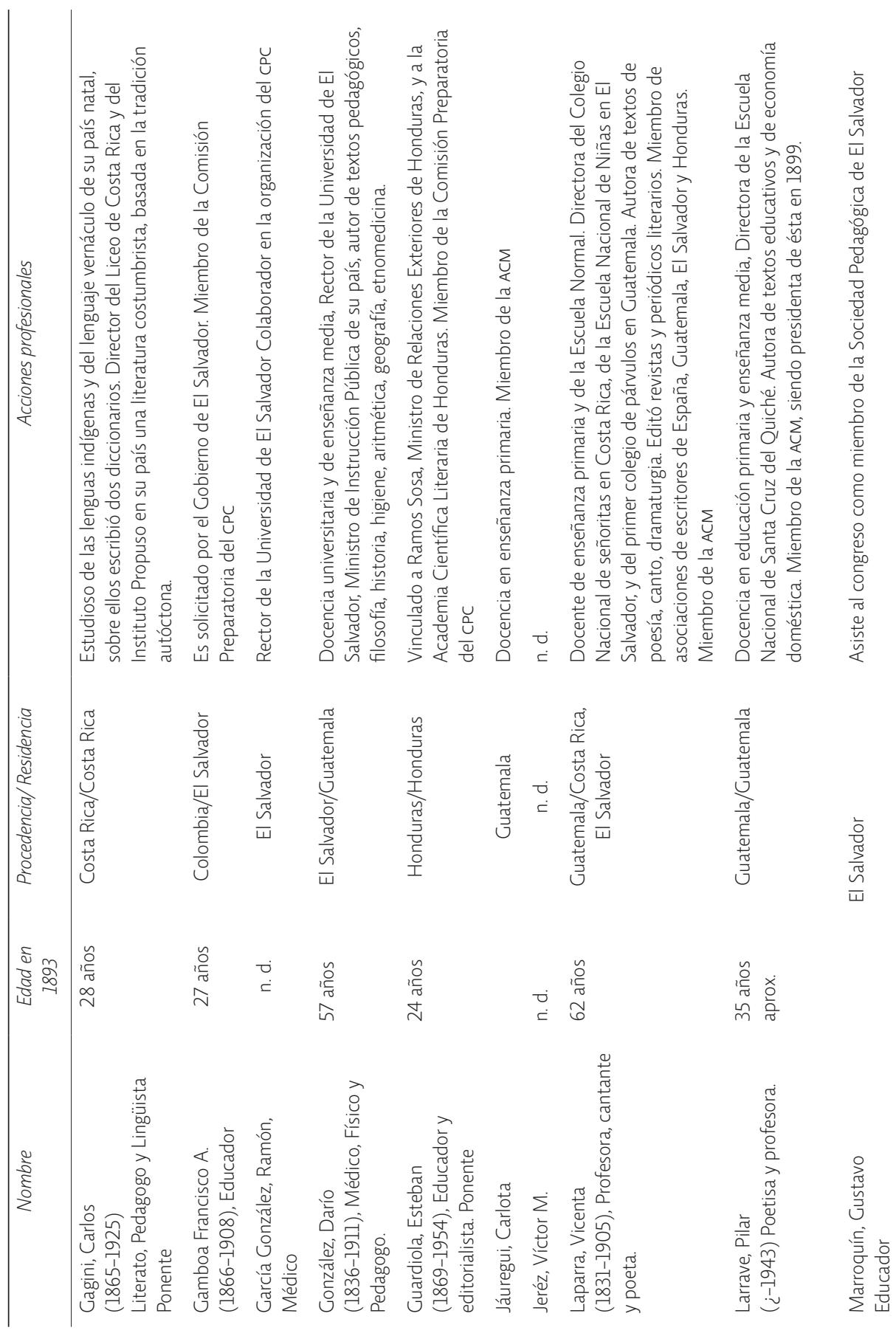




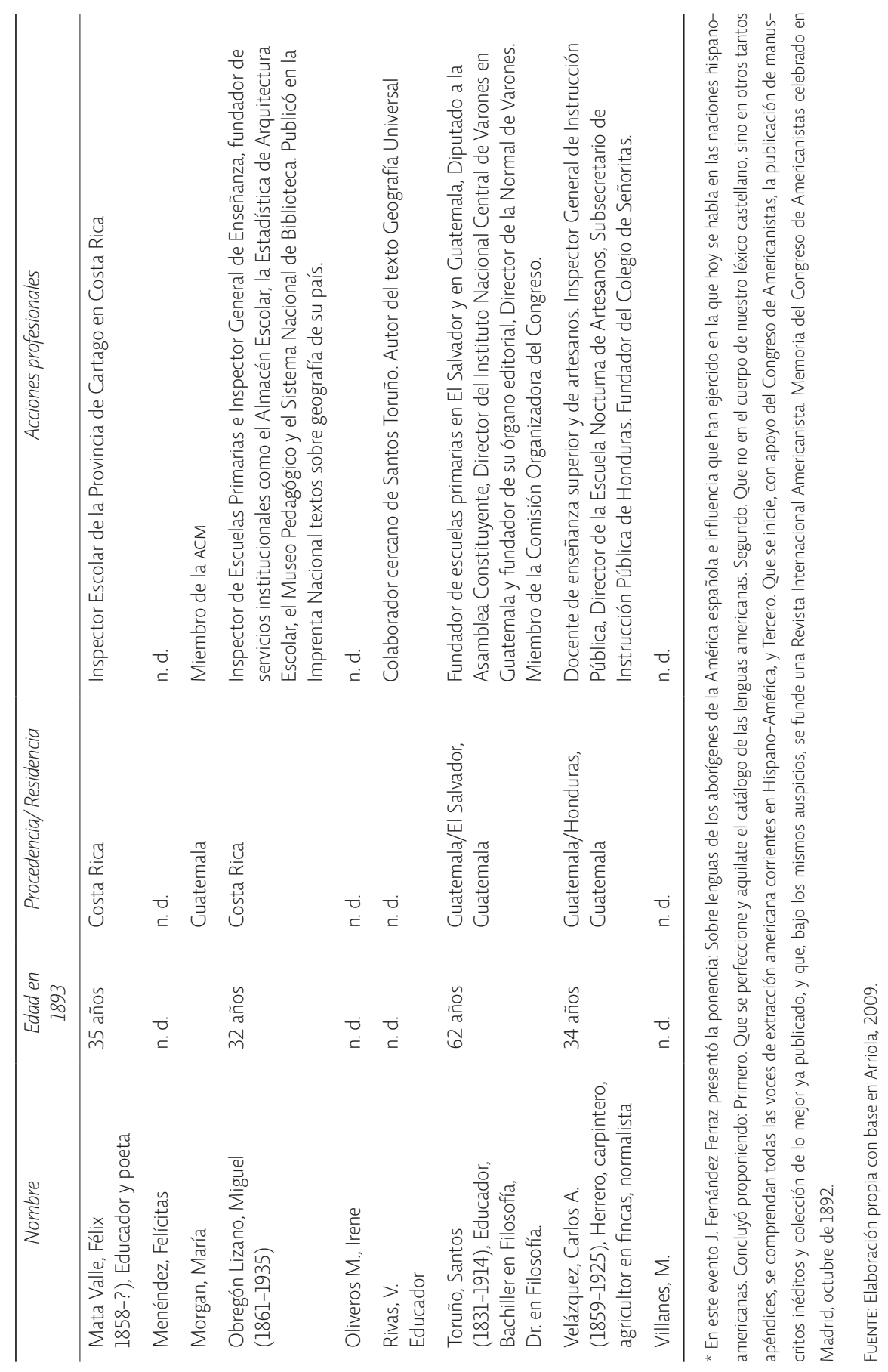


tos de enseñanza como el celebrado Colegio de Utatlán en el reino Quiché, ${ }^{10}$ hoy se encuentra en el estado de postración más lamentable (CPC, 1893: 346-347).

Como Ferraz, Guardiola se apoya también en las lecturas de Washington Irving ${ }^{11}$ sobre el panorama y destino de los pueblos indígenas, a partir de tres razones: la muerte o destrucción de sus pueblos; la degeneración de la raza por efecto del embrutecimiento y estado salvaje; y cruce de razas en que a la larga domine la raza más fuerte y bien constituida. Ambos ven al indio como una raza pujante, con entrañable amor a la libertad y al trabajo que engrandece y dignifica; consideran que serán absorbidos por las necesidades de las sociedades industriales; esto es, transportes, minas y servicios urbanos. Esta idea se vincula con otra percepción de educadores como Carlos Gagini, quien observa que en algunos lugares como Costa Rica, la mayoría de indígenas hablan castellano y no oponen resistencia a las influencias civilizatorias y aceptan el trato frecuente con población blanca, si bien hay excepciones como los Guatusos (CPC, 1893: 339). En Guatemala, Pilar Larrave refiere que los indios del oriente y norte de Guatemala "ya no visten el traje primitivo ni se alimentan tan sobria y mezquinamente... viven en habitaciones algo cómodas, [...] se asocian de los ladinos en sus negocios y apenas recuerdan el dialecto de sus antepasados"; mientras que los del occidente "viven aislados en cabañas mal cubiertas o diseminados por los valles y montañas [...] conservan el lenguaje, trajes y costumbres primitivas" (CPC, 1893: 360).

Guardiola coincide en que el indio sin instrucción pone en desorden el proceso de trabajo y la vida social de las instituciones en Centroamérica, principalmente porque más de la mitad de la población es indígena, y porque algunos blancos o ladinos se han aprovechado de las riquezas naturales, sin pensar en ningún beneficio para los indios y en la paz de la región.

Pilar Larrave de Castellanos refiere que las migraciones no han beneficiado las formas de vida de los indios al ser éstos tratados como esclavos: carecen de derechos, son maltratados y embrutecidos, lo que ha propiciado que el indio sea "cobarde y con tendencia a la traición, débil de carácter y terco en sus creencias, e intemperante por añadidura" (CPC, 1893: 362); una manera de ser que transmite lástima y desprecio. La forma de vida ancestral del indio carece de necesidades por falta de conocimiento sobre cómo satisfacer otras condiciones de vida. Con el escaso trabajo que realiza cotidianamente satisface con facilidad lo que le es útil para vivir, carece de industrias que le permita mejorar el trabajo manual y agrícola que realizan. La falta de aspiraciones no les permite tener ambiciones, y abandonar "su mezquino carácter". Señala que el indio se halla como en tiempos de la colonia: "Solamente cesaron los

\footnotetext{
${ }_{10}$ Sin saber la razón precisa por la que se resalta el Colegio de Utatlán, podría suponerse que se debe al conocimiento arqueológico sobre de esta ciudad quiché, lugar donde se sugiere fue escrito el Popol Vuh, en el siglo XVI. Utatlán pertenece al Municipio de Sololá, al sur occidente de la República de Guatemala.

${ }^{11}$ Washington Irving (1783-1859), uno de los primeros diplomáticos y escritores de Estados Unidos que alcanzó gran popularidad por sus obras literarias sobre culturas locales de pueblos aborígenes de América, Europa y Asia.
} 
sacrificios humanos y las luchas de pueblo en pueblo, de tribu a tribu. Cesaron aquellos odios, y el indio se volvió tímido, desconfiado, cobarde, debido quizá a los medios de destrucción de que se valieron los castellanos para sojuzgarlo" (CPC, 1893: 360). Si bien considera que el indio es interesado, terco, pusilánime y aferrado a sus preocupaciones, la influencia de los misioneros y otras circunstancias sociales lo han beneficiado, al introducirlo a la civilización.

Como parte de las conclusiones votadas, se acuerda integrar al indio al modo de organización planteado por los Estados nacionales de la región, procurando mantener valores y formas tradiciones de organización para el trabajo y vida comunitaria; aunque existen diferentes puntos de vista sobre la conservación de las lenguas indígenas y la obligatoriedad de la lengua oficial del español; todo ello en beneficio de una paz étnica y política, y de los bienes económicos de la nación. El poder de los puntos acordados en el Congreso (CPC, 1893: 177-188) a partir del voto individual legitima la manera de entender cómo es el indio y sus necesidades "[...] por fin, la conciencia de los dominadores parece recordarles la deuda que tienen contraída para con los dueños de este fecundo suelo, que forman más de los dos tercios de nuestra población, y que, sin embargo, han permanecido ajenos a la vida civilizada, llevando irrisoriamente el nombre de ciudadanos" (CPC, 1893: 177). Sobresale en el marco de esta afirmación la preocupación étnica, política y económica del futuro de la población criolla como minoría y encontrarse en medio de las contradicciones de los regímenes independentistas, para consolidarse en beneficio de una sociedad nacional en paz y organizada para el beneficio de su economía.

Ninguna época más afortunada que la presente para emprender la gran cruzada en pro de los indios;... Un clamor unísono se levanta, pidiendo que el aborigen venga a confundirse con nosotros en un solo pueblo, en una sola nación; a gozar de los elementos de vida y de progreso de que disfrutamos; a conseguir juntamente con nosotros los fines sociales e individuales que son propios del ser racional [...]. Pero si se quiere llevar a buen término esa aspiración, [...] se necesita de voluntad firme, perseverante y enérgica, para vencer los innumerables obstáculos, las porfiadas resistencias, que los dominadores, por sus preocupaciones y por interés, y los dominados, por hábito y por temor, presentarán a la obra mil veces benéfica de los que intentan redimir a una raza, y hacer brotar hombres; producir ciudadanos, donde sólo existen seres desgraciados que se han acostumbrado a pasar por autómatas [...]. Si de buena voluntad queremos hacer el bien a los indios, pensemos que son nuestros hermanos, hundidos en las tinieblas de la ignorancia, postrados en triste abatimiento, embotados sus espíritus; porque hemos hecho sus dominadores todo lo posible para extinguir en ellos la chispa de la inteligencia, para arrancarles todo sentimiento de dignidad, temerosos sin duda de que el grito terrible de venganza se revolviera contra los que les hemos arrebatado patria, hogar, libertad, y todo lo que les pertenecía, hasta la propiedad de su persona [...]. Si queremos ser justos, no le reprochemos al indio falta de 
aptitudes, inferioridad de facultades ni perversión de sentimientos; que si esos defectos tienen, de nosotros y no de él es la culpa (CPC, 1893: 178).

\section{La escuela como medio eficaz para civilizar al indio}

Los educadores emiten una serie de recomendaciones para los gobiernos centroamericanos, iniciando por el lugar donde deben encontrarse las escuelas. Plantean un territorio o varios, conforme al número de diferencias raciales, "etnográficas"12 y lingüísticas. Éstos deberán ser inalienables y para uso exclusivo de los indígenas. Que se reduzca a poblado las tribus errantes existentes aun, con prudente persuasión, acatando sus prácticas y respetando sus lugares. Las autoridades que se encarguen de la administración y gobierno de dichos territorios ejercerán sólo en nombre del Estado, de la Provincia o del Municipio una especie de patronato, para que los aborígenes organicen su propio gobierno local y puedan deliberar libremente, ${ }^{13}$ a partir de una ley nacional de protectorado. Es conveniente facilitarles un patrimonio seguro, es decir, dar en propiedad a los habitantes de estos asentamientos, como los ya formados anteriormente por indígenas, terrenos para el cultivo y elementos para el trabajo. Sobre nombrar o no tutores para los pueblos indios, existen discrepancias entre los ponentes, pues algunos como Esteban Guardiola argumentan que los llamados tutores se convierten en explotadores de los pobladores. Se acuerda finalmente la presencia de funcionarios como tutores de los indígenas, para fungir como guardianes de sus derechos, promotores de sus intereses. Que se permita el flujo migratorio de indígenas, a fin de que los hacendados contraten a todos los que soliciten empleo y no sólo a los que tienen conocimientos agrícolas.

Se plantea que cada país centroamericano organice uno o varios centros docentes de formación agrícola, industrial y comercial, sin sacar al indio demasiado de sus nativas costumbres, donde puedan educarse un número proporcionado de ellos en su propia lengua. Cada determinado tiempo, esto es, cuando se encuentren con el grado de cultura necesaria, podrán con recursos públicos migrar a otros pueblos indígenas y dedicarse a la docencia, donde deberá haber al menos una escuela. Que existan escuelas normales de indios, donde se formen profesores de instrucción primaria y de enseñanza de artes y oficios. Establecer escuelas para las mujeres indígenas donde aprendan, además de la instrucción necesaria, los oficios domésticos que más puedan servirles. Considerar la apertura de escuelas dominicales para los que no puedan asistir diariamente a la escuela.

\footnotetext{
12 Término empleado por los congresistas.

${ }^{13}$ El uso de formas tradicionales para organizarse colectivamente pareciera ser un elemento civilizador que reconocen y valoran como positivo los congresistas.
} 
Deben crearse escuelas de artes para los que deseen aprender un oficio o cualquier arte. Los profesores de estas escuelas deberán saber la lengua de sus alumnos para darse a entender con ellos en los primeros días de asistencia, oír sus conversaciones y comunicarse con los padres de familia. Deben ser bien retribuidos, y se les premiará a los que mejores resultados presenten en exposiciones de frutos y trabajos realizados en la escuela.

En las poblaciones indígenas deberán estimularse nuevos oficios, por lo que se recomienda la migración de laboriosos europeos y japoneses para que establezcan otras industrias en la región; pero no debe alejárseles demasiado de sus costumbres ni de su idioma, donde recibirán nociones prácticas de agricultura y de modestas industrias, además de aprender los principales contenidos de la instrucción primaria, y evitar comportamiento como el vicio de la bebida y la antipatía hacia los ladinos.

Que las autoridades administrativas aporten la subsistencia para que los hijos de las familias indígenas vayan a la escuela, mediante la creación de internados, y ayuda a los indios pobres. La alimentación del niño indígena debe ser nutritiva y variada. Todo alumno que ingrese a la escuela deberá calzarse, vestir honestamente, asearse y peinarse con esmero diariamente.

\footnotetext{
Las manifestaciones exteriores de la cultura del hombre y las diferencias especiales que lo distinguen del no civilizado, no son otras que el traje, los hábitos y costumbres, y, finalmente, el idioma. Así, al indígena que habla el castellano, que viste a la europea, ya no le llamamos indio, ya no lo distinguimos de la raza mixtada: y si además tiene los hábitos y costumbres de los ladinos, es tan culto como ellos, y con ellos se asimila, se mezcla y se confunde. (срc, 1893: 182).
}

Se cuestiona el uso de la fuerza bruta para civilizar a los indígenas, el indio no asistirá voluntariamente a la escuela, por ello se propone medidas directivas, como estimularlos con premios adecuados a sus deseos o merecimientos. Cada director escolar debe llevar un libro de registro, que compruebe la asistencia de los indígenas inscritos en el registro civil. Exigirle al padre de familia multas por la inasistencia de hijos e hijas. Los impuestos y multas deberán estar en relación con sus producciones y circunstancias. Se les debe prohibir que contraigan matrimonio mientras no obtengan el certificado de haber concluido la escuela elemental.

\section{Organización escolar}

En cuanto a las habilidades docentes se acuerda que la práctica, la observación y la buena voluntad sean los mejores consejeros. Se reduzca el número de horas de estudio para los indígenas; que las escuelas sean lo más atractivas posibles; y se les facilite el aprendizaje concen- 
trándolo a lo estrictamente necesario (CPC, 1893: 181) y las competencias escolares que realicen los profesores sean de agricultura, con procedimiento existentes y adecuados en el país. Para Gamboa, el interés del indio se encuentra en dar fortaleza a su raza, por ello la educación física, la salud del cuerpo, la estética y el dibujo son indispensables para la apreciación de sí mismo.

Es preciso que el indio tenga suficiente vigor para entrar en lucha por la vida con cualquiera otra raza que un día u otro inmigre a su país, pues nadie tiene más derecho que él para vencer en suelo americano a quien quiera que venga a combatirlo bataIlando por la existencia,.. Debe el indio conocer, siquiera sea muy someramente, las instituciones del país en que vive, para que conozca sus derechos y sepa las obligaciones que debe cumplir como ciudadano, derechos que la ley le garantiza, y obligaciones que por esa misma ley le son impuestas (CPC, 1893: 371).

Estas dos últimas ideas remiten a considerar en el indígena el derecho y la responsabilidad de ser parte de una nación que siente propia. Plantea que el aprendizaje de un oficio responde a la influencia del dibujo lineal y natural, presente en la cultura estética y moral, y que su aplicación práctica está en el desarrollo de un objeto artístico o de un oficio. "Un oficio manual y, si es posible una arte bella, como la música o la pintura, elevarán al indio del nivel de jornalero, al de artesano o al de artista, y se habrá verificado en él por el trabajo o el sentimiento, una redentora transformación" (CPC, 1893: 372). Advierte que el trabajo ha sido entendido por la influencia religiosa como una maldición de Dios, pero ciertamente es una ley ineludible de toda existencia. El trabajo ha llevado a los pueblos laboriosos a realizar grandes obras, no obstante, el trabajo realizado por los indígenas como bestias de carga no les ha permitido verlo con un espíritu superior de hombre culto. El indio,

[...] en contacto directo con la espléndida naturaleza americana, tiene vivo, palpitante y ávido el sentido estético; ... debe procurarse que los cantos escolares, en idioma indígena, versen sobre temas que halaguen los sentimientos de la raza que se quiere civilizar conforme a sus tradiciones, y que les hagan amable nuestra civilización. Esos cantos pueden aprovecharse también para consignar en ellos ciertos conocimientos elementales sobre historia del país y sobre artes y ciencias. Concluye su intervención señalando con interés el deseo de contribuir en la tarea de enaltecer y redimir a los antiguos y naturales dueños y señores del continente americano (CPC, 1893: 372).

Los educadores del Congreso acuerdan una enseñanza basada en ideas prácticas, con aplicación a las artes y oficios, mientras se van adaptando a nuevas maneras de ser y hacer; pero existen diferencias en cuanto a mantener sus lenguas y tradiciones, y la dedicación a los contenidos de la enseñanza primaria. Pilar Larrave argumenta: "Comencemos por hacerle entrar a la escuela desde la edad de cuatro a cinco años, hagamos que olvide su dialecto, 
proporcionémosle vestido decente y sencillo pero abrigado, procuremos que su alimentación sea, aunque frugal, sana y nutritiva, acostumbrémosle a paseos escolares y habremos dado un buen paso en su civilización" (CPC, 1893: 362-363).

Se acuerdan escuelas mixtas para niños indios y ladinos de cuatro a cinco de edad, donde podrán asistir de las diez de la mañana a las dos de la tarde. Las primeras horas de la mañana se emplearán en el cultivo de los campos. Que se cuente con tres años de enseñanza elemental y dos de complementaria. En la elemental aprenderán a leer y escribir correctamente, las cuatro primeras reglas de la Aritmética, generalidades de Historia y Geografía universal, Gramática castellana, trabajos manuales, dibujo lineal, nociones de agricultura, moral, urbanidad y religión. En la segunda enseñanza ampliarán esas nociones y además lecciones de Geografía e Historia de Centro América.

Gamboa recomienda que el libro de lectura para los indios sea

\begin{abstract}
elaborado conforme a los principios de la pedagogía moderna, debe estar dispuesto de modo que contenga, en artículos cortos, aquello que más pueda interesar a la parte estética y moral de los indígenas, tenidos en cuenta su carácter, sus costumbres, sus tradiciones y el medio especial en que viven y han vivido. El libro contendrá también, dispuestos gradualmente y de la manera más lógica, artículos de corta extensión sobre ciencias físicas y naturales, sobre la agricultura e industria, etc., etc. [...]. Otra parte muy interesante de dicho libro es la parte poética, que no debe faltar en él. Me parece que las poesías deben ser todas sencillas, hechas de preferencia en versos de arte menor y sobre temas que interesen la imaginación de los indígenas o que les inculquen alguna enseñanza moral [...] con cuantas láminas sea posible, de modo que se objetiven en él los conocimientos y hechos que contenga [...]. De este libro, lo mismo que de los demás que se usen como auxiliares en la enseñanza, se deberán hacer dos ediciones; una en lengua indígena, hasta donde sea posible la adaptación, y otra en castellano (CPC, 1893: 369).
\end{abstract}

Para la enseñanza de la Caligrafía recomienda el uso del método propuesto por el español Juan García Purón, ${ }^{14}$ en cuadernillos con pensamientos que comprenden cultura intelectual, moral o estética de los educandos. Las lecciones seguirán un orden progresivo de comprensión u aplicación a la vida práctica. La aritmética se enseñará de la misma manera en otras escuelas primarias, aplicable al comercio y los problemas sean referidos a las ordinarias y sencillas transacciones que realiza el indio. Las lecciones de cosas deben aprovechar el mundo natural en que vive para ampliar su conocimiento que observa diariamente y le son útiles,

14 El médico español Juan García Purón (1852-1912), emigró de joven a México, estudió Medicina se graduó como coronel médico en el ejército mexicano. Se estableció en Nueva York en 1884, donde compaginó el ejercicio de la medicina y la dirección de la sección de la lengua castellana de la editorial neoyorkina Appleton y Compañía, donde produjo obras de divulgación científica. 
y todo aquello que puede necesitar más adelante para ejercer un oficio manual con el que pueda ganarse la vida. La geografía deberá ser práctica también, empezando por la localidad en que vive, como cualquier otra persona, para de allí extenderse a la topografía y producciones de su país, después la posición que ocupa éste respecto de los países vecinos. Se harán a partir de la geografía, aplicaciones históricas, especialmente de la época precolombina, procurando los hechos relevantes de sus antepasados, "lo que les será muy grato y les servirá de estímulo en la idea de elevarse de nuevo y, ventajosamente, al nivel que alcanzaron sus venerables antecesores" (CPC, 1893: 370).

Sobre la enseñanza religiosa, Vicenta Laparra defiende la inclusión de la enseñanza religiosa de la iglesia católica porque ésta evitaría que los indios civilizados se levanten a reclamar sus derechos, al no aprobarse la venganza y el odio entre hermanos. Convencida afirma que la creencia es la fuerza moral de las masas populares: "Amará a Dios sobre todas las cosas y a tu prójimo como a ti mismo" (CPC, 1893: 379). Propone también la organización de sociedades benéficas a favor de los indígenas, y que puedan familias asilar a niños indígenas en sus domicilios, "enseñándoles sus deberes para con Dios, para con ellos mismos, para con sus semejantes, y hasta con los animales".

No se les prohibirá el ingreso en la vida social de familias civilizadas, concluye. Si lo desean los egresados de la enseñanza primaria complementaria, podrán realizar otros estudios, preferentemente en las escuelas normales, o donde aprendan el desempeño de puestos públicos. Aprendidos hábitos de limpieza, lectura y escritura del idioma castellano, podrán inscribirse en los institutos nacionales indígenas, propuestos para cada nación federativa.

\section{Conclusiones}

Entre los argumentos de los educadores del Congreso Pedagógico Centroamericano de 1893, sobresale la falta de valoración al indio y la necesidad de someterlo a las formas de organización y convivencia social que el orden político norma y legitima en razón de un orden y progreso social y económico. Los educadores ejercen su derecho a plantear cómo la escuela debe intervenir en el programa político del Estado, y desde esa perspectiva abordan el primer tema del congreso: ¿Cuál será el medio más eficaz para civilizar a la raza indígena, en el sentido de inculcarle ideas de progreso y hábitos de pueblos cultos? Las condiciones de pobreza, injusticia y dominación de los indios son tratadas por los educadores como realidades naturalmente negativas y diferentes al modo de vida de los criollos, ladinos o europeos. Las carencias que observan en el indio son vistas como defectos y, por tanto, elementos a redimir. Pueden aceptar que en un tiempo pasado los pueblos indígenas fueron grandes, y que fueron despojados de sus bienes, lenguas y culturas por 
acciones de frailes, finqueros y leyes injustas, pero domina en sus apreciaciones el desprecio, el racismo y el desentendimiento de un futuro propio, basado en el derecho y libertad a hablar sus lenguas y conservar sus tierras y costumbres.

El plan civilizatorio acordado en el congreso consistía en enseñarle al indio lo que le faltaba para parecerse al ladino: lengua, vestido, vivienda y hábitos de higiene y de comportamiento. Recomendaban que mantuviera el trabajo agrícola y manual como medio para manutención y que viviera en terreros asignados exclusivamente para ellos; que se cuidara la asistencia del indio a las escuelas, las cuales debían ubicarse en lugares cercanos, y pudieran desenvolverse ante cualquier autoridad institucional con obediencia ya sea educativa, comercial, agrícola o jurídica. Imponer una educación intencionalmente restringida para modificar el sentido de vida de una población es racismo intelectual.

El indio fue reconocido como una fuerza económica necesaria para la unidad de la región en términos de paz y orden social. Al ser éste educado podían las élites políticas y letradas confiar en un bienestar material y los educadores, aliados a esa estructura de poder, lograron acordar un plan estratégico para civilizar a los indios y mantener los planes de un gobierno que prometía progreso y libertad. El pensamiento positivista dio forma y sentido a esas propuestas educativas, y dio fortaleza a las instituciones escolares y estructuras de la administración pública. Cabe mencionar que el positivismo no significó una fuerza de oposición al poder eclesiástico, se integró a él como un elemento necesario para preservar el orden y la paz social.

Finalmente, el análisis de los trabajos realizados por los educadores en este Congreso permitió adentrarse a las formas de pensar del positivismo y al ejercicio profesional de educadores en diferentes países de una región particular. Se trae al presente la complejidad de una problemática latinoamericana, no obstante el reconocimiento de acuerdos internacionales de las naciones multiculturales, entre ellos: derechos étnicos, lingüísticos, interculturales, ambientales, de género. Como antes, los educadores están articulados a las políticas nacionales y regionales y a intereses de diferentes grupos con poder económico y político, y aunque pueden distinguirse diferencias sustanciales entre ellos sus diferentes formas de participación contribuyen a analizar desde diferentes perspectivas la legitimidad y proyección al trabajo escolar.

\section{Bibliografía}

Argueta Hernández, Bienvenido (2011), El nacimiento del racismo en el discurso pedagógico, vol. I, El Instituto Agrícola de Indigenas, Guatemala, PACE-GIS.

Arriola, Jorge Luis (2009), Diccionario Enciclopédico de Guatemala, 2 ts., Guatemala, Universidad de San

Carlos de Guatemala. 
Barillas, Edgar (1989), El problema del indio durante la época liberal, Guatemala, Instituto de Investigaciones Históricas, Antropológicas y Arqueológicas-USAC (Temas monográficos núm. 2).

Bourdieu, Pierre (1978), "Racisme de l'intelligence", Coloquio 'Races, sociétés et aptitudes' de UNESCO (MRAP), mayo de 1978, Cahiers Droit et liberté, núm. 382, pp. 67-71.

Cambranes, Julio (1977), El imperialismo alemán en Guatemala. El tratado de comercio de 1887, Guatemala, IIES/Universidad San Carlos de Guatemala.

Casaús Arzú, Marta Elena (2010), El lenguaje de los ismos: algunos conceptos de la modernidad en América latina, Guatemala, F\&G Editores.

Fernández Ferraz, Juan (1892), "Sobre lenguas de los aborígenes de la América Española e influencia que han ejercido en la que hoy se hablan en las naciones Hispano-Americanas", Ponencia presentada en la Exposición Histórica Americana, Madrid, 30 de Octubre de 1892, en Memorias, Sección primera. Filología, pp. 485-491, documento pdf disponible en: <http://cvc.cervantes.es/lengua/congreso_literario/pdf/CVC_congreso_484.pdf > (consulta: 04/05/2012).

Gómez Isa, Felipe (coord.) (2004), Racismo y genocidio en Guatemala, 2a ed., San Sebastián, Instituto Derechos Humanos Pedro Arrupe/Fundación Rigoberta Menchú, documento pdf disponible en: <http://www.mugengainetik.org/archivos/racismo\%20y\%20genocidio\%20en\%20guatemala.pdf > (consulta: 15/05/2012).

González Ponciano, J. Ramón (1991), "'Del café, los indios y el lluminismo'. El Instituto Agrícola de Indígenas durante el gobierno del general José María Reina Barrios (1892-1898)", en Memoria del encuentro de intelectuales. Chiapas-Guatemala, San Cristóbal de Las Casas, Chiapas, celebrado del 5 al 9 de junio de 1990, Instituto Chiapaneco de Cultura/Gobierno del Estado de Chiapas, pp. 17-24.

Memorias del Primer Congreso Pedagógico Centroamericano de 1893 (CPC) (1893), Guatemala, s/e, documento pdf disponible en: <http://www.archive.org/stream/primercongresope00guat\#page/4/ mode/lup> (consulta: 11/10/2011).

Meneses Morales, Ernesto (1998), Tendencias educativas oficiales en México. 1821-1911, 2ª ed., México, Centro de Estudios Educativos/Universidad Iberoamericana.

Ordóñez Cifuentes, José Emilio Rolando (1991), "Constitución y derechos étnicos México/Centroamérica", en Aspectos nacionales e internacionales sobre derecho indígena, México, Instituto de Investigaciones Jurídicas/Universidad Nacional Autónoma de México, pp. 191-231.

Revista México Intelectual (1892) (varios números), Veracruz, México, Escuela Normal de Jalapa.

Torres Valenzuela, Artemis (2010), "El positivismo, concepto civilizador en Guatemala", en Marta Elena Casaús Arzú (coord.), El lenguaje de los ismos: algunos conceptos de la modernidad en América Latina, Guatemala, F\&G Editores, pp. 97-124.

Amalia Nivón Bolán. Universidad Pedagógica Nacional, Unidad Ajusco. Doctora en Antropología Social. Líneas de investigación: Educación multicultural e historia de la educación. Publicaciones recientes: (2011), "La compleja figura del actor educativo en México a finales del siglo XIX”, en Dalia Ruíz Ávila (coord.), Cuerpos académicos. Vía alterna hacia la investigación, México, Universidad Pedagógica Nacional, pp. 263-275 (Serie Horizontes Educativos); (2011), "Las tesis sobre educación de 2009 en la ciudad de México. Mensajes al mar en una vasija de esperanza", Anuario Educativo 2009, México, Universidad Pedagógica Nacional; Educación intercultural. Material de comprensión-expresión escrita, Textos de apoyo didáctico para estudiantes universitarios indígenas, México, Universidad Pedagógica Nacional, 
2012 (en prensa); Evaluación: Material de comprensión-expresión escrita, Textos de apoyo didáctico para estudiantes universitarios indígenas, México, Universidad Pedagógica Nacional, 2012 (en prensa).

Recibido: 6 de junio de 2012

Aceptado: 7 de agosto de 2012 